\title{
Endoscopic Treatment of Intussusception due to Intestinal Tuberculosis
}

\author{
Dooyoup Kim¹, Hyundo Jung', Mindae Kim¹, Jaehyung Lee', Sukhun Kim¹, Dongku Kang', Jiha Kim¹ and Ilseon Lee ${ }^{2}$ \\ Department of ${ }^{1}$ Internal Medicine and ${ }^{2}$ Pathology, Bongseng Memorial Hospital, Busan, Korea
}

Traditionally, adult intussusception has required a bowel resection because of the malignancy risk. A patient with anorexia, weight loss, and abdominal pain visited our clinic. A physical exam and imaging study revealed no acute peritoneal signs. A colonoscopy for biopsy and bowel reduction was attempted. The tissue sample was consistent with intestinal tuberculosis. We report intestinal tuberculosis complicating intussusception which was treated without surgical intervention. Clin Endosc 2017;50:206-208

Key Words: Tuberculosis; Intussusception; Colonoscopy

\section{INTRODUCTION}

Tuberculosis can affect any part of the gastrointestinal tract. ${ }^{1}$ The symptoms of intestinal tuberculosis are non-specific. Obstruction, perforation, or ischemia can occur as the disease progresses. ${ }^{2}$

Adult intussusception is rare. Pediatric intussusception is far more common than the adult type. Between $1 \%$ and $5 \%$ of intestinal obstructions in adults are caused by intussusception. ${ }^{3,4}$ An identifiable lead lesion is found in $70 \%-90 \%$ of intussusception cases. ${ }^{5,6}$

\section{CASE REPORT}

A 64-year-old Korean man with weight loss, anorexia, and abdominal pain was admitted.

The patient's blood pressure was 109/69 mm Hg, his body

Received: May 23, 2016 Revised: September 19, 2016

Accepted: October 13, 2016

Correspondence: Mindae Kim

Department of Internal Medicine, Bongseng Memorial Hospital, 401 Jungang-daero, Dong-gu, Busan 48775, Korea

Tel: +82-51-664-4201, Fax: +82-51-664-4209, E-mail: mdmdk69@hanmail.net

(cc) This is an Open Access article distributed under the terms of the Creative Commons Attribution Non-Commercial License (http://creativecommons.org/ licenses/by-nc/3.0) which permits unrestricted non-commercial use, distribution, and reproduction in any medium, provided the original work is properly cited. temperature was $38.1^{\circ} \mathrm{C}$, his heart rate was 88 beats per minute, and his respiratory rate was 20 breaths per minute. On physical examination, coarse crackles were audible in the right lung. A soft mass was palpable in the right lower abdomen. The patient did not have neurologic impairment or related medical history.

The patient's white blood cell count was $11.6 \times 10^{9} / \mathrm{L}$, his hemoglobin was $13.5 \mathrm{~g} / \mathrm{dL}$, his platelet count was $396 \times 10^{9} / \mathrm{L}$, and his C-reactive protein was $12.3 \mathrm{mg} / \mathrm{dL}$. Tumor markers were within the normal range. A sputum acid-fast bacilli stain, sputum culture, and polymerase chain reaction were positive for Mycobacterium tuberculosis.

Plain chest X-ray showed consolidations with cavities (Fig 1). Simple abdomen X-ray showed no significant obstruction (Fig 2). On a contrast-enhanced abdominal computed tomography (CT) image (Fig. 3), the bowel wall was overlapped in a donut shape, and multiple mesenteric lymph nodes were enlarged.

The patient was without acute peritoneal signs and not in urgent clinical condition. A colonoscopy was scheduled to obtain a biopsy that could rule out malignancy. Bowel preparation using the usual laxative amount was accomplished without abdominal pain or complications. There was a report that bowel preparation should be performed with caution because it may accelerate intussusception. ${ }^{7}$ However, there was also a report that a colonoscopy had been used to diagnose the exact level of intussusception and reduce intussusception by air infusion. ${ }^{8}$ 


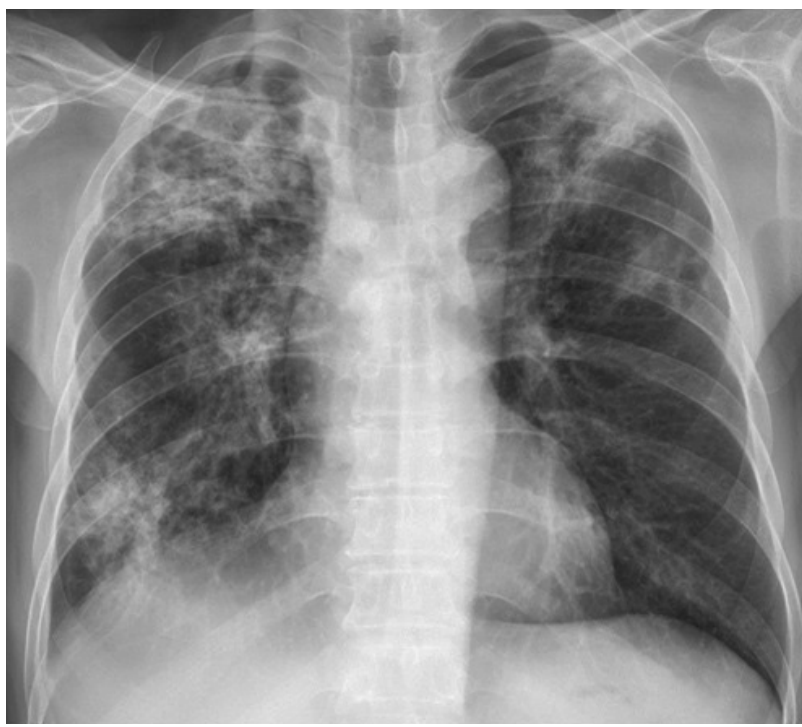

Fig. 1. Chest radiogram showing typical cavitary lesions in both upper lobes.

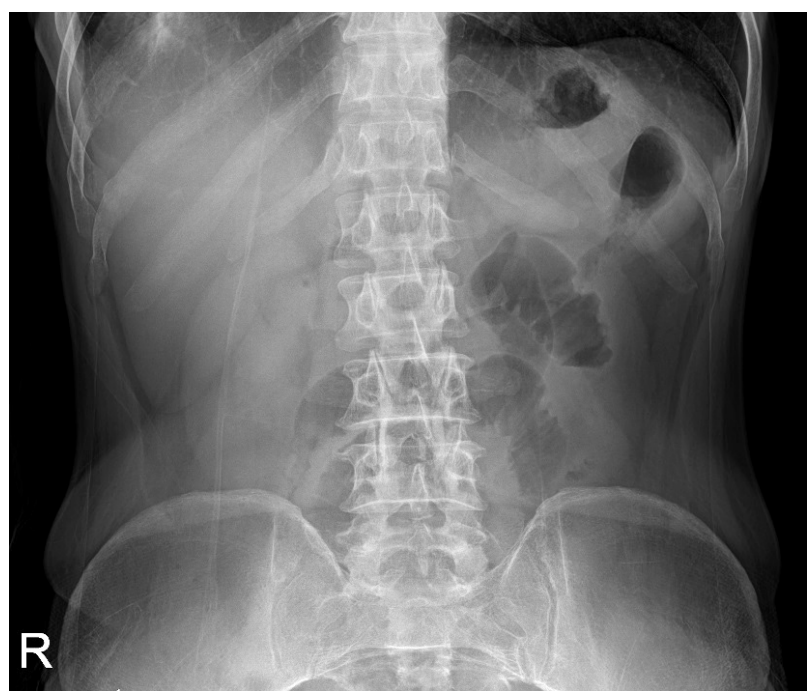

Fig. 2. Simple abdomen showing no significant bowel obstruction.

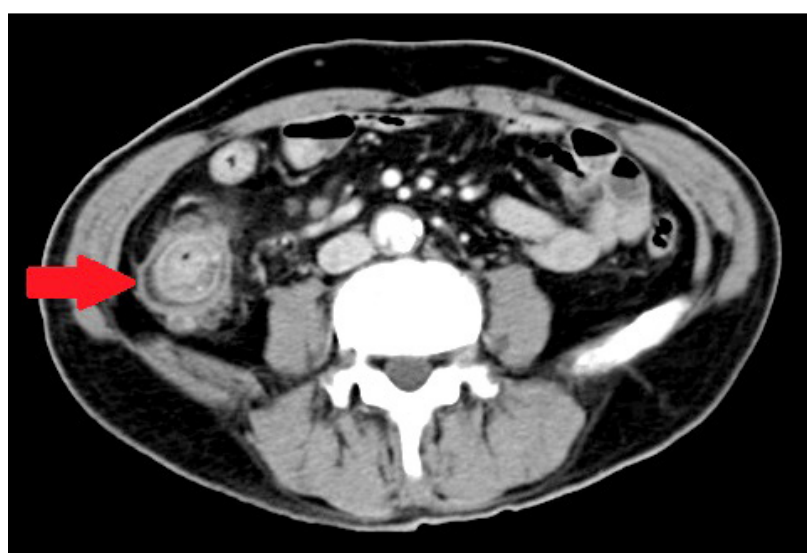

Fig. 3. Abdominal computed tomography (CT) showing the target lesion with alternating densities, which were the intussusceptum (inner layer) and intussuscepien (outer layer) (arrow).

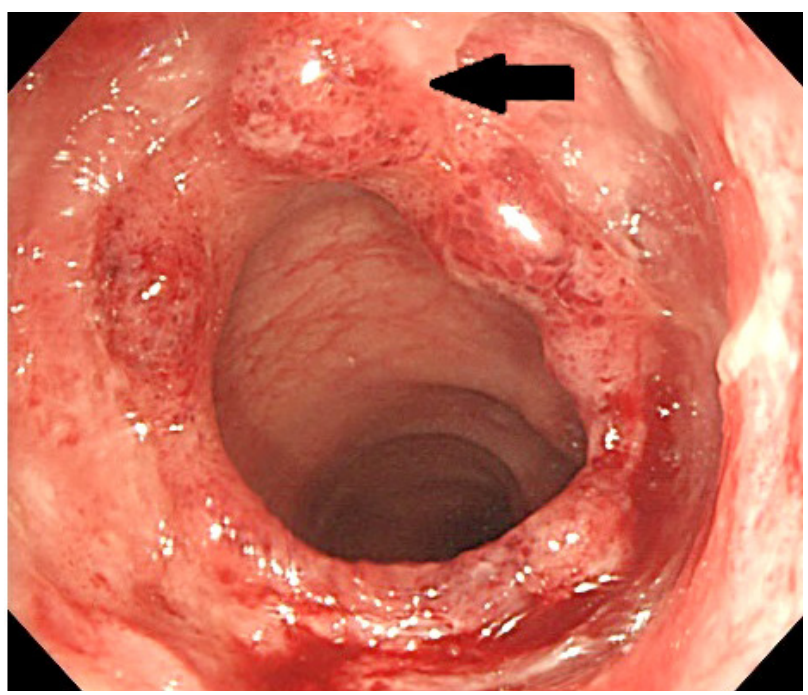

Fig. 4. Asymmetric hypertrophied masses on the ileum on colonoscopic view (arrow).

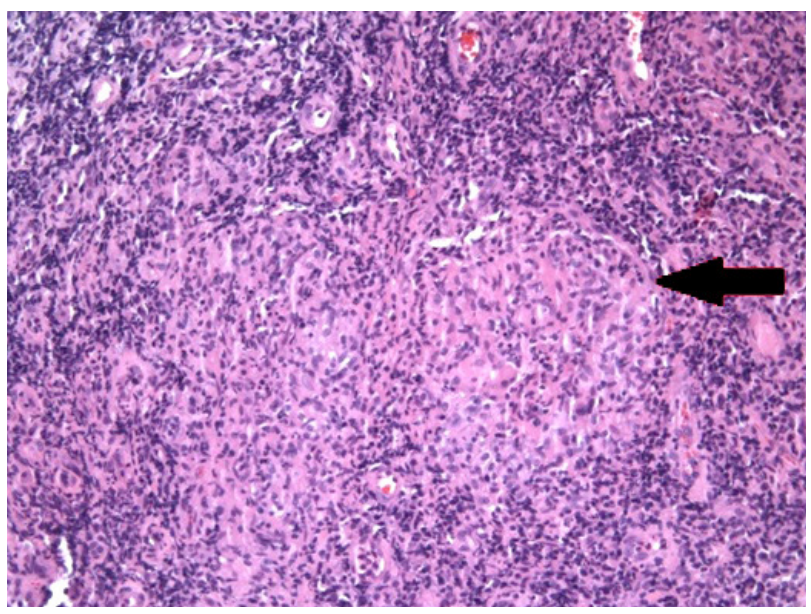

Fig. 5. Endoscopic biopsy tissue exposed caseating granuloma (arrow) (H\&E stain, $\times 100)$.

An asymmetric hypertrophied mass on the ileum was noted in the endoscopy (Fig. 4). Manual reduction of the intussusception was achieved using air infusion. No image was taken before the intussusception reduction. The biopsy results indicated an ulcerative, necrotic, and inflammatory lesion with a granuloma, which is consistent with intestinal tuberculosis (Fig. 5). There was not a high degree of dysplastic or tumor cells.

A round of standard anti-tuberculosis medication was administered and the patient's symptoms were relieved.

\section{DISCUSSION}

Intussusception is a serious condition in which a segment of the intestine slides into an adjacent part of the intestine. ${ }^{9}$ Most 
cases of adult intussusception are the result of an underlying clinical condition. Adult intussusception presents without specific symptoms. Benign masses and adhesion are the most common causes of small bowel intussusception, causing about $90 \%$ of cases. ${ }^{10,11}$ Adenocarcinoma is the most common cause of large bowel intussusception. ${ }^{12}$

Abdominal CT is a useful tool in diagnosing intussusception. ${ }^{13}$ The typical CT finding is an inhomogeneous target or sausage-shaped mass. The mesenteric vessels and fat can be seen between the bowel walls. ${ }^{12}$ Colonoscopy is a useful tool for diagnosing adult intussusception., ${ }^{4,14,15}$ A colonoscopy can confirm and localize the intussusception while also revealing the underlying lead point lesion. Polypectomy of the lead point is not recommended because of the high risk of perforation and necrosis of the bowel.

The conventional management method is a surgical resection using an oncologic technique because the underlying medical conditions often involve malignancy. Preoperative reduction of intussusceptions is not recommended because it can cause tumor cell seeding and weaken the mucosal wall. The prognosis is generally favorable after surgery. Metastases in the small intestine result in the poorest prognosis in adult intussusception.

Intestinal tuberculosis is caused by Mycobacterium tuberculosis or atypical mycobacterium, the latter being associated with acquired immune deficiency syndrome (AIDS). ${ }^{16}$ The postulated mechanisms by which the tuberculosis bacilli reach the gastrointestinal tract are hematogenous spread, ingestion of bacilli in sputum, and through lymph channels from infected nodes. ${ }^{1}$ The most frequent site of involvement is the ileocecal junction.

Diagnosis is usually confirmed by radiologic, endoscopic, and histologic modalities. ${ }^{1}$ Asymmetric thickening of the colonic wall and enlarged necrotic lymph nodes were highly suggestive CT findings. ${ }^{17}$ Using an endoscopic biopsy, diagnosis is possible if the acid-fast bacillus (AFB) stain or caseating granuloma is positive. Treatment of intestinal tuberculosis is the same as that of pulmonary tuberculosis, unless there are acute abdominal signs. ${ }^{18}$

Adult intussusception caused by intestinal tuberculosis was reported by Nakamura et al. ${ }^{9}$ and Kang et al. ${ }^{19}$ In both cases, segmental resection of the bowel was performed. This case had a different therapeutic approach as endoscopic reduction was performed. It is suggested that a more conservative treatment is plausible unless acute abdomen or high malignancy risk is present.

The traditional treatment plan for adult intussusceptions has been changing. Kim et al. suggested that, if the length of the intussusception is shorter than $3.5 \mathrm{~cm}$ and there is no leukocytosis and no obstruction, manual reduction by endoscopy can be safely attempted. ${ }^{20}$ We report a case of intussusception due to intestinal tuberculosis and suggest a more conservative approach to treating adult intussusceptions to avoid unnecessary bowel resections.

\section{Conflicts of Interest}

The authors have no financial conflicts of interest.

\section{REFERENCES}

1. Sharma MP, Bhatia V. Abdominal tuberculosis. Indian J Med Res 2004:120:305-315

2. Ha HK, Ko GY, Yu ES, et al. Intestinal tuberculosis with abdominal complications: radiologic and pathologic features. Abdom Imaging 1999;24:32-38.

3. Azar T, Berger DL. Adult intussusception. Ann Surg, 1997;226:134-138.

4. Begos DG, Sandor A, Modlin IM. The diagnosis and management of adult intussusceptions. Am J Surg 1997;173:88-94.

5. Coleman MJ, Hugh TB, May RE, Jensen MJ. Intussusception in the adult. Aust N Z J Surg 1981;51:179-180.

6. Nagorney DM, Sarr MG, McIlrath DC. Surgical management of intussusceptions in the adult. Ann Surg 1981;193:230-236.

7. Park KJ, Choi HJ, Kim SH, et al. Sigmoidorectal intussusception of adenoma of sigmoid colon treated by laparoscopic anterior resection after sponge-on-the-stick-assisted manual reduction. World J Gastroenterol 2006;12:146-149.

8. Kim JH, Kim YB, Kwak ST. Two cases of malignant lymphomas in the terminal ileum causing intussusception: diagnosis and reduction of intussusception by colonoscopy. Korean J Gastrointest Endosc 1999;19:650-656.

9. Nakamura S, Yanagihara K, Izumikawa K, et al. Severe pulmonary tuberculosis complicating ileocecal intussusception due to intestinal tuberculosis: a case report. Ann Clin Microbiol Antimicrob 2008;7:16.

10. Erbil Y, Eminoğlu L, Caliş A, Berber E. Ileocolic invagination in adult due to caecal carcinoma. Acta Chir Belg 1997;97:190-191.

11. Alkim C, Saşmaz N, Alkim H, Cağlikülekçi M, Turhan N. Sonographic findings in intussusception caused by a lipoma in the muscular layer of the colon. J Clin Ultrasound 2001;29:298-301.

12. Tan KY, Tan SM, Tan AG, Chen CY, Chng HC, Hoe MN. Adult intussusception: experience in Singapore. ANZ J Surg 2003;73:1044-1047.

13. Gayer G, Apter S, Hofmann C, et al. Intussusception in adults: CT diagnosis. Clin Radiol 1998;53:53-57.

14. Hurwitz LM, Gertler SL. Colonoscopic diagnosis of ileocolic intussusception. Gastrointest Endosc 1986;32:217-218.

15. Thomas AW, Mitre R, Brodmerkel GJ Jr. Sigmoidorectal intussusception from a sigmoid lipoma. J Clin Gastroenterol. 1995;21:257.

16. Boudiaf M, Zidi SH, Soyer P, et al. Tuberculous colitis mimicking Crohn's disease: utility of computed tomography in the differentiation. Eur Radiol 1998;8:1221-1223.

17. Marshall JB. Tuberculosis of gastrointestinal tract and peritoneum. Am J Gastroenterol 1993;88:989-999.

18. Balasubramanian R, Nagarajan M, Balambal R, et al. Randomized controlled clinical trial of short course chemotherapy in abdominal tuberculosis: a five-year report. Int J Tuberc Lung Dis 1997;1:44-51.

19. Kang HS, Kang JY, Kang HH et al. A case of adult intussusception induced by intestinal tuberculosis. Tuberc Respir Dis 2010;69:196-200.

20. Kim JS, Lim JH, Jeong JH, Kim WS. [Conservative management of adult small bowel intussusception detected at abdominal computed tomography]. Korean J Gastroenterol 2015;65:291-296. 